\title{
Third Molar Surgery: The Effect of Primary Closure, Wound Dressing and Metronidazole on Postoperative Recovery
}

\author{
Lt Col J B Lyall \\ FDSRCS, RADC \\ Dept of Military Dental Surgery, RAM College, Millbank, London SW1P 4RJ
}

SUMMARY: One hundred and forty eight patients with bilateral symmetrically impacted lower third molars entered $\frac{2}{8}$ clinical crossover trial to compare the effects on postoperative recovery of a Bismuth Iodoform Paraffin Paste (BIPPI socket dressing, primary closure using a resorbable suture (Softgut) and to ascertain if prophylactic metronidazole influenced the outcome. The results reaffirm the surgical principle that contaminated surgical wounds such as third molar sockets are best kept open with a dressing. Attempts at primary closure should be resisted if there is no intentiog to prescribe antibiotic cover. However, if a suitable antibiotic is taken then primary closure using a resorbable suture ca $\overline{\vec{\pi}}$ be carried out with confidence. This may reduce the need for outpatient follow up.

\section{Introduction}

Investigations to reduce postoperative discomfort following third molar surgery have been principally directed at either local treatments to the wound or systemic preparations such as antibiotics and analgesics. The only recent investigation comparing both modalities is that of Hellem and Nordenram(1) who showed that sockets dressed with gauze sponge soaked in Whitehead's varnish suffered fewer post-operative symptoms compared with systemic penicillin, lincomycin and placebo. More recently, Holland and Hindle(2) used the model of bilateral symmetrically impacted third molars where one socket was dressed with BIPP impregnated ribbon gauze and the other socket closed completely. They reported less pain and swelling on the dressed side.

The value of antibiotics in third molar surgery is still questioned. Many clinicians support the use of penicillin following the comprehensive study by $\operatorname{Kay}(3)$ but Macgregor and Addy(4) recommend that its use is restricted to more difficult cases even though they found it reduced swelling and trismus but not pain. However, Curran et al(5) found no evidence to support the need for penicillin in third molar surgery, the risk of side effects outweighing any marginal advantages it may have. Neither do Happonen et al(6) who found placebo equally as effective as penicillin and tinidazole but in both these studies little regard was given to operative technique. In contrast, Rood and Murgatroyd(7) reported that metronidazole reduced the incidence of dry sockets following routine extractions and Kaziro(8) showed that it reduced pain and swelling in third molar surgery.

The aim of this study was essentially to repeat that of Holland and Hindle and to determine whether the addition of prophylactic metronidazole influenced the resuit.

\section{Patients and Method}

One hundred and forty eight consecutive patient's gave written consent to enter the study which had bees approved by the Army Medical Services Reseatich Executive. They had to be fit and healthy with bilate $\vec{l}$ symmetrically impacted lower third molars $\frac{9}{\circ}$ as determined on clinical and orthopantomogam examination. Uncomplicated upper third molars cबil be extracted at the same time since they very ragely cause postoperative problems. The patients vere admitted to either British Military Hospital (BM Rinteln or BMH Hannover. On admission they were randomly allocated to either a control or metronidazoli group and were given instructions and a diary card fơ completion at home. Each patient received a standard pack of thirty analgesic tablets (Solpadeine), two to bo taken as needed but not exceeding eight tablets each day. In addition, the metronidazole group were give $400 \mathrm{mg}$ metronidazole orally for two days commencing two hours pre-operatively. To avoid bias, the surgeop was unaware which group he was treating and the patient was not informed which treatment method was to be applied to each operative side nor given and indication as to possible outcome.

\section{Operative technique}

All operations were performed under generis anaesthetic by one of four surgeons using a previous agreed technique and the duration of the operation was recorded. A buccal and lingual flap was raised in each case using an envelope type incision. In all cases, bone was removed with chisels employing a lingual split wher necessary and any tooth division was performed using $\Phi$ drill. The degree of difficulty was graded as simple moderate or difficult following set criteria and everte effort was made to ensure each side received the same surgery. 
Closure method for each patient:

Side 1. Complete closure was achieved by Softgut sutures, the flap margins being trimmed if needed to prevent implantation of epithelium.

Side 2. A $2 \mathrm{~cm}$ piece of bismuth iodoform paraffin paste (BIPP) impregnated ribbon gauze was placed in the socket. A silk suture was inserted through one flap, the upper end of the dressing and then the other flap such that the wound margin was prevented from closing by primary intention.

\section{Observations}

On the diary card, pain observations were recorded after each postoperative twenty four hour period and swelling observations on the second and fifth day. Patients compared one side of their mouth to the other. They recorded whether one side was more swollen or painful, equally so or less than the other side.

On the seventh postoperative day the diary cards were collected and the socket dressing was removed. A persistently painful socket for which treatment was requested was recorded and managed by standard local measures with antibiotics if indicated.

Statistical analysis was carried out using methods described by Armitage and Berry(9). Comparability of patient age and duration of operation between the two groups was verified using the 2-sample t-test on normalised data. Sex ratio and degree of difficulty were examined by the chi-squared test. A normal based test for differences in 2 proportions (incorporating a continuity correction) was used to detect differences in the presence or absence of postoperative pain and swelling. Of those who did notice a difference in pain or swelling between sides a test based on the binomial distribution was applied to determine if the true proportion of those with less pain or swelling differed significantly from an expected value of 0.5 . Wound healing comparisons were made using a chi-squared test. Probability value of $<0.05$ were taken as significant.

\section{Results}

One hundred and forty patients completed the trial with seventy patients in each group. Of the eight who did not, three patients stopped taking metronidazole because of nausea, one required readmission for haemorrhage, and four failed to complete their cards properly. The two groups were found to be comparable with respect to age, sex ratio, degree of difficulty and duration of operation (Table 1).

\section{Pain}

Figs 1 and 2 illustrate the pain experience between dressed and closed sides for the control and metronidazole groups. There are no significant differences in the numbers of patients recording no pain on either side or in the number of patients reporting a difference in pain between sides. However, of those patients who did notice a difference in pain between
Table 1

Group comparability data. $\mathrm{SD}=$ standard deviation. There are no significant differences between groups.

\begin{tabular}{lccc}
\hline & mean & $\begin{array}{c}\text { Metronidazole } \\
\text { Group }\end{array}$ & $\begin{array}{c}\text { Control } \\
\text { Group }\end{array}$ \\
\hline Age: $(\mathrm{yr})$ & SD & 22.4 & 22.2 \\
& & 2.6 & 2.8 \\
Duration of & mean & 16.6 & 16.1 \\
Operation: (min) & SD & 5.2 & 5.4 \\
& & & \\
Sex: & female & 27 & 28 \\
& male & 43 & 42 \\
Difficulty of & Simple & 21 & 28 \\
Operation: & Moderate & 42 & 35 \\
& Difficult & 7 & 7 \\
\hline
\end{tabular}

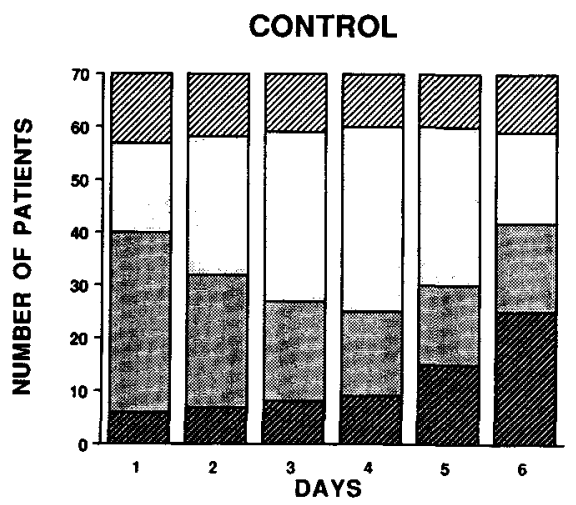

$D>C$

$\square \mathrm{D}<\mathrm{C}$

$\mathrm{D}=\mathrm{C}$

0 No pain both sides

Fig 1. Pain experience in Control Group. $D=$ Dressed $C=$ Closed. More patients have less pain on the Dressed side: day 2 , $p<0.05$; Day $3, p<0.01$; day $4 p<0.001$; day 5 , $p<0.01$.

METRONIDAZOLE

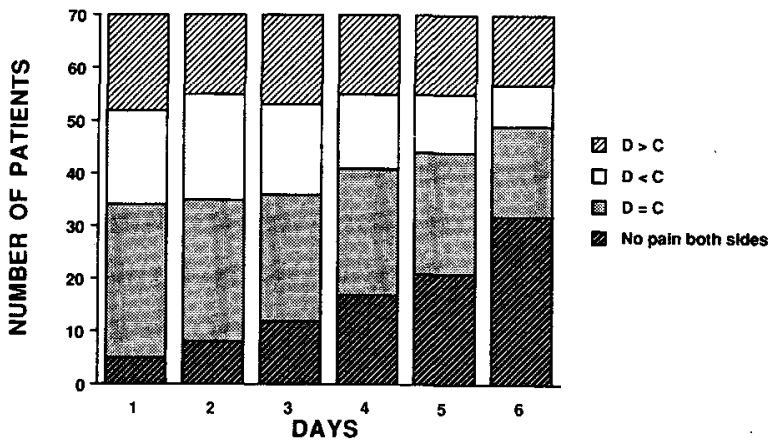

Fig 2. Pain experience in Metronidazole group. $D=$ Dressed, $C=$ Closed. There are no significant differences between Closed and Dressed sides. 
sides in the control group, a greater proportion of patients experienced less pain on the dressed side on the second to fifth postoperative days only (day $2 \mathrm{p}<0.05$, day $3 \mathrm{p}<0.01$, day $4 \mathrm{p}<0.001$, day $5 \mathrm{p}<0.01$ ). In the metronidazole group there was no significant difference between the sides on any day.

\section{Swelling}

Table 2 shows the swelling experience of the two groups on the second and fifth postoperative days. Significantly more patients reported no swelling on either side in the metronidazole group on the fifth day $(p<0.05,95 \%$ confidence interval $-0.3-0.01)$. Considering only those patients where a difference in swelling existed, the proportion of patients with less swelling on the dressed side was significantly greater in the control group on both days $(p<0.05)$. However the opposite occurred in the metronidazole group with the closed being less swollen on the fifth day $(p<0.05)$.

\section{Wound healing}

Table 3 illustrates the results of wound healing. In the control group a significantly greater number of sockets closed primarily were persistently painful which required further treatment compared with the dressed side $(p<0.02)$. In the metronidazole group there was no difference between sides.

\section{Discussion}

The trial design, using bilateral symmetrically impacted third molars allows comparisons between operative treatments to be made with greater confidence especially when the teeth are moved at the same time. Patients decided whether one side differed from the other in pain and swelling over a six day period. This avoided the need to use pain and swelling scores which are difficult to measure as evidenced by the variety of schemes available. Another advantage of using this simple format is that when studying the effect of additional systemic treatments, comparable groups of patients can be assessed without the need for a placebo in a control group (Sims, personal communication).

The results indicate that primary closure of lower third molar sockets causes more pain and swelling compared with sockets dressed with BIPP gauze when no prophylactic metronidazole is taken. This is in agreement with the findings of Holland and Hindle(2). However, when prophylactic metronidazole was prescribed there appeared to be no difference in pain experience between sides and less overall swelling was reported on the fifth day especially for sides closed primarily, although at the lowest level of significance.

The complications following the removal of impacted lower third molars have been attributed to operative trauma, wound infection and increased fibrinolysis of the blood clot. Both trauma and infection can cause inflammation resulting in pain and swelling $(10,11)$. Since both groups were comparable in degree of
Table 2

Distribution of postoperative swelling (no. of patients). $D$ Dressed; $\mathrm{C}=$ Closed. Control group: less swelling on the dressed side on both days $(* \mathbf{p}<0.05)$. Metronidazole group: less swelling on the closed side on day $5(+p<0.05)$. More patients in the metronidazole group reported no swelling both sides $(\uparrow p<0.05)$ 응

\begin{tabular}{|c|c|c|c|c|c|}
\hline & Post-op & & & & no swelling \\
\hline \multirow{3}{*}{$\begin{array}{l}\text { Control } \\
\text { Group }\end{array}$} & day & $\mathrm{D}=\mathrm{C}$ & $\mathrm{D}<\mathrm{C}$ & $\mathrm{D}>\mathrm{C}$ & both sides \\
\hline & 2 & 14 & $34^{*}$ & 17 & 5 \\
\hline & 5 & 15 & $32^{*}$ & 15 & 8 \\
\hline \multirow{3}{*}{$\begin{array}{l}\text { Metronidazole } \\
\text { Group }\end{array}$} & $\begin{array}{l}\text { Post-op } \\
\text { day }\end{array}$ & $D=C$ & $\mathrm{D}<\mathrm{C}$ & $D>C$ & $\begin{array}{l}\text { no-swelling } \\
\text { both sides }\end{array}$ \\
\hline & 2 & 12 & 21 & 33 & 4 \\
\hline & 5 & 7 & 16 & $28+$ & $19 \ddagger$ \\
\hline
\end{tabular}

Table 3

Wound healing. Closed sides in the control group were morê? likely to require further treatment $(* p<0.02)$.

\begin{tabular}{|c|c|c|c|}
\hline & & $\begin{array}{c}\text { Control } \\
\text { Group }\end{array}$ & $\underset{\text { Group }}{\text { Metronidazole }} \stackrel{\stackrel{\sim}{\circ}}{\stackrel{2}{\circ}}$ \\
\hline $\begin{array}{l}\text { Further } \\
\text { treatment } \\
\text { required: }\end{array}$ & $\begin{array}{c}\text { Dressed } \\
\text { Closed }\end{array}$ & $\begin{array}{c}7 \\
16^{*}\end{array}$ & To \\
\hline
\end{tabular}

difficulty and operating time any differences foựd? between them should be attributable to other factors.

In the pre-antibiotic era contaminated surgisap wounds were dressed followed by delayed primw suture or allowed to heal by secondary intention in oreto to minimise the risks of postoperative infection. A les rigid practice is often applied to the face and jaws due tळe the age-old surgical principle attributed to their profuse blood supply. However, Borthen et al(12) showed tha 5 the mouth is a heavily contaminated environment with some 300 species of organisms present, especially. anaerobes. Despite good aseptic techniques and woun toilet, extraction wounds contain not only bacteria bu들. also bone and cementum chips, squames and probably variety of other surgical debris(13). Keeping the wound open with a dressing may allow inflammatory exudate and any haematoma collection to escape carrying with it any contaminants. Perhaps saliva entering the wound may aid healing as suggested by Simpson(14). Primary closure would prevent such escape and could result ing more pain and swelling which could explain the results found in the control group.

The addition of systemic metronidazole only remove anaerobic bacteria from the wound. Since closed an dressed sides were similar for pain experience in the metronidazole group anaerobic bacterial contamination appears to be more important than the operative treatments carried out. This important role of bacteria is in agreement with previous studies by Seymour et al $(15)$ 
Bystedt et al(16) and Mitchell(17). However, in the control group at one week postoperatively there was no difference in pain between sides which suggests that any bacteria present had been overcome by the normal host defences, perhaps because of the profuse blood supply mentioned earlier. Indeed, recent experimental evidence from Knighton et al(18) suggests that oxygen is as good as any prophylactic antibiotic.

The insertion of dressings into third molar sockets has had a chequered history in oral surgery since some agents have been shown to delay would healing when applying histological criteria in animal experiments $(19,20)$. In this study, dressed sides in the metronidazole group were more swollen compared to closed sides even though pain experience was similar, which may be a reflection of properties associated with the dressing. However, less pain and swelling occurred on the dressed side in the control group, which again suggests that anaerobic bacterial contamination overides any difference between the operative treatments.

Further treatment for persistently painful sockets is much more likely to occur after primary closure with no antibiotic cover. The term dry socket is deliberately avoided since different criteria have been used in various studies by McGregor and Addy(4), Bystedt et al(16), $\mathrm{Kay}(3)$. Its aetiology appears to be multifactorial although increased fibrinolysis of the blood clot may be the final common pathway as described by $\operatorname{Birn}(10)$. Using the term "persistently painful socket" instead does not suggest any cause but implies that healing is not progressing normally and it would be incorrect to compare percentage figures with such studies.

From a military viewpoint, lower third problems predominantly affect young adults and contribute a substantial proportion of sickness in a Service population. Most cases require in-patient surgery and since military hospitals cover a wide geographical area outpatient follow up is difficult. This study indicates that primary closure of third molar sockets using a resorbable suture and prophylactic metronidazole can not only be carried out with confidence but also removes the need for suture removal and reduces the need for postoperative follow up thus minimising time off duty..

\section{Acknowledgements}

My sincere thanks go to Col P Newlyn, Lt Col J Fleet and Lt Col R M H Phillip formerly at BMH Rinteln and BMH Hannover for their surgical help and to Mrs M Sims of Med Stats, MOD Stanmore for her statistical evaluation of the data.

\section{REFERENCES}

1. Hellem S, Nordenram A. Prevention of postoperative symptoms by general antibiotic treatment and local bandage in removal of mandibular third molars. Int J Oral
Surg 1973; 2: 273-8.

2. Holi.AND C S, Hinde M O. The influence of closure or dressing of third molar sockets on postoperative swelling and pain. Br J Oral Maxillofac Surg 1984; 22:65-71.

3. KAYL W. Investigations into the nature of pericoronitis II. Br J Oral Surg 1966; 4:52-78.

4. MacGregor A J, AdDY A. Value of penicillin in the prevention of pain, swelling and trismus following the removal of ectopic mandibular third molars. Int J Oral Surg 1980; 9:166-9.

5. Curran J B, Kennett K, Young A R. An assessment of the use of prophylactic antibiotics in third molar surgery. Int J Oral Surg 1974; 3:1-6.

6. HAPPONEN R P, BaCKSTROM A C, YlypaAVALNiEmi P. Prophylactic use of phenoxymethylpenicillin and tinidazole in mandibular third molar surgery, a comparative placebo controlled clinical trial. $\mathrm{Br} J$ Oral Maxillofac Surg 1990; 28:12-5.

7. ROOD J P, Murgatroyd J. Metronidazole in the prevention of dry sockets. Br J Oral Surg 1979 17:62-8.

8. KAzIRo G S. Metronidazole (Flagyl) and arnica montana in the prevention of post-surgical complications, a comparative placebo controlled trial. Br J Oral Maxillofac Surg 1984; 22:42-9.

9. Armitage P. Berry G. Statistical Methods in Medical Research. 2nd ed. Oxford: Blackwell Scientific Publications, 1987, 106-25 205-8.

10. BIRN H. Etiology and pathogenisis of fibrinolytic alveolitis Int J Oral Surg 1973; 2:211-4.

11. Sweet J B, Butler D P. Predisposing and operative factors: effect on the incidence of localised osteitis in mandibular third molar surgery. Oral Surg 1978; 46:206우 10 .

12. Borthen L, Heimdahl A, Nord C E. Selectiveg suppression of the anaerobic oropharangeal microflora with local metronidazole. Br J Oral Maxillofac Surg 1987 25:49-53.

13. MacGregor A J. The impacted lower wisdom tooth. Oxford New York Toronto: Oxford University Press. $1985,94$.

14. SimpSon H E. Experimental investigation into the healing of extraction wounds in macacus rhesus monkeys. $J$ Oral Surg 1969; 18:391-395.

15. Seymour R A, Meechan J G, Blatr G S. An investigation into postoperative pain after third molar surgery under local analgesia. Br J Oral Maxillofac Surg 1985; 23: 410-8.

16. Bystedt H, von KonOw L, Nord C E. Effect of Tinidazole on Postoperative Complications after Surgical Removal of Impacted Mandibular Third Molars. Scand J Infect Dis 1981; Suppl 26 135-9.

17. Mrtchel. D A. A controlled clinical trial of prophylactic tinidazole for chemoprophylaxis in third molar surgery, $\mathrm{Br}$ Dent J 1986; 160:284-6.

18. Knighton D R, Halliday B, Hunt T K. Oxygen as an antibiotic: the effect of inspired oxygen on infection. Arch Surg 1984; 119:199-204.

19. Carroll P B, Melfi R C. The histological effect of topically applied acetysalicylic acid on bone healing in rats. Oral Surg Oral Med Oral Pathol 1972; 33, 728-32.

20. Summers L, MALZ L. Extraction wound sockets. Histological changes and paste packs - a trial. Br Dent J 1976; 141:377-80. 


\title{
Historical Vignette - The Death of an Australian Army Doctor on Thursday Island in 1915 after Envenomation by a Stonefish
}

\author{
Maj N K Cooper \\ FRCS(Ed), RAMC \\ Trainee in Occupational Medicine \\ AMD5a, Room 509, First Avenue House, High Holborn, London WCIV $6 H E$
}

Thursday Island was named as such by Captain Cook who first sighted it on that day, and since that time it has attracted the attention of at least one medically qualified writer(1). It lies in the Torres Strait between continental Australia and Papua New Guinea at latitude $10^{\circ} 30^{\prime} \mathrm{S}$. and longitude $142^{\circ} 3^{\prime} \mathrm{E}$. Because of the speed of tidal flow in this narrow strait and the proximity of the much larger Hammond, Horn, Prince of Wales and Friday Islands, Thursday Island offers a relatively safe anchorage. Since the 1880 s it has been the centre of government for the area(2).

A hospital was built near the main port area of Thursday Island by the Queensland Government towards the end of the last century. Visitors to Victoria Parade, the main area of waterfront by the hospital which was named after the then Queen Empress, are confronted by an impressive granite memorial. This bears the inscription:- "A Tribute to the Memory of Joseph Leathom Wassell M B, ChM Syd. who laboured in Thursday Island for 15 years. Loved and honoured by all, 7th April 1915.

Further examination of this memorial and of Dr Wassell's tombstone in the Thursday Island cemetery reveals the deceased to have been a Captain in the Australian Army Medical Corps (AAMC), and to have succumbed to the effects of "stingray poisoning." The latter phrase is highly intriguing, as remarkably few deaths have been attributed to the effects of this particular marine venom, the authoritative work on this subject stating:- "Only in rare cases of severe (stingray) envenoming are such (systematic) effects seen ..."(3).

Earlier in the same work a description is given of:"the one or two ragged spikes on the tail" which "should be carefully avoided" as they inject the stingray venom. The author continues:- "Stingrays tend to feed on the sea bed and people tread on them or swim low over them ... a Stingray's response to contact may be a sudden thrust of its tail forward and downwards, driving the spike into the victim".

I first saw Dr Wassell's memorial on Thursday Island in 1977, shortly after completing my internship at Cairns Base Hospital some 600 miles to the south. Victims of tropical fish envenomation attended the Cairns Base Casualty Department with a regularity of one to two cases per month. The first aid treatment for recent fish stings was to immerse the affected part (usually a hand or a foot) in water which was as hot as the patient could bear, as all fish venoms (stone fish, stingray, lion fish, weever fish) are thermolabile at mammalian body

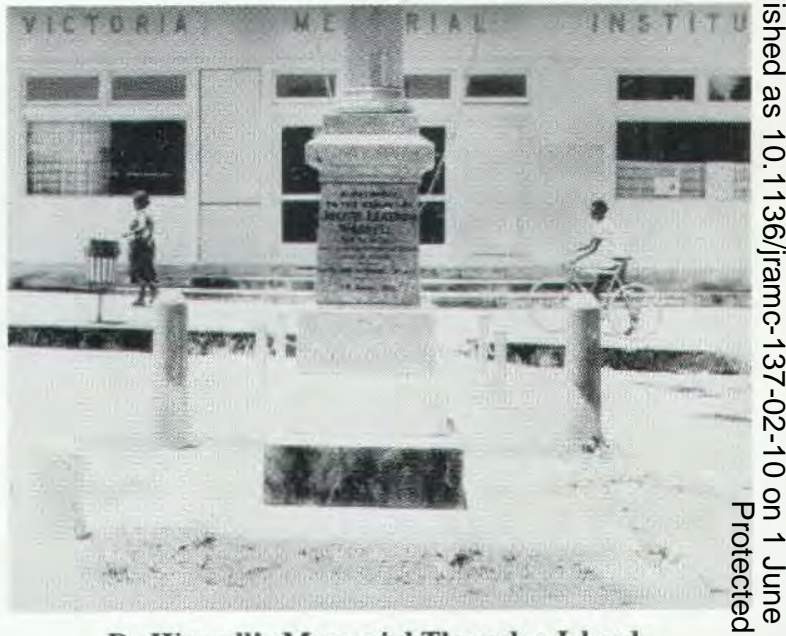

Dr Wassell's Memorial Thursday Island.

temperature(3). Pain relief is often quite substantial using this measure, but has to be supplemented in mo cases by local anaesthesia or nerve block. Tetants prophylaxis and surgical debridement as necessary would then be given.

In the case of stingray injuries which were a day or $\stackrel{\mathbb{Q}}{2}$ more old, those for instance in fishermen who had $\overrightarrow{\overrightarrow{0}}$ sustained their injuries on the outer barrier reef, urgent $\overline{3}$ surgical debridement was usually required, and often $\underset{F}{F}$ required general anaesthesia for its performance. The violent actions of a stingray spike in the flesh of the victim lead to tissue necrosis which summates with the action of the venom injected, as well as with the effects of bacterial contamination and retained integument $\vec{\nabla}$ from the spike. The end result of delayed treatment may therefore be extensive tissue loss necessitating skin grafting. Sutherland(3) summarises the situation thus:- $\frac{0}{3}$ "The wounds are potentially contaminated with bacteria,". but may contain (in addition) a trail of glandular and integumentary sheath material as well as necrotic tissue. "

The pathological scene depicted on Dr Wassell's memorial is therefore, on the balance of probabilities, $\frac{T}{0}$ one of death from septicaemia. In 1915 the antibiotic era was some 30 years in the future, and Paul Ehrlich's N "magic bullets" had not as yet materialised, even in the" form of an early sulphonamide such as Prontosil. N However a literature search made the picture even more $\omega$ intriguing with the following account(4) - "In 1915 the quarantine and health officer at Thursday Island, 
Queensland, DrJ L Wassell was fishing on a coral reef, and, while wading about in sandshoes trod on a large stone fish."

The account continues: "Although its spines had to penetrate his shoe, so much poison was injected into his foot that he died within a few days. Doubt as to whether his death was due to the sting has, however, been expressed by Dr H Flecker (5) of Cairns, who maintained that most cases of stone fish wounds were trivial injuries."

A reading of Dr Flecker's 1956 letter of doubt to the Medical Journal of Australia(5) reveals the following:"It (the stone fish - Synanceja species) is a particularly hideous and repulsive-looking fish which lies lazily on the sandy bottom, well camouflaged, resembling somewhat a very dirty, drab and grimy piece of boulder with patches of green algae. Moreover it will not move unless disturbed.

Despite the common belief that this fish frequently produces death, no authentic record of any such casualty which will bear the light of critical investigation can be found in any literature. A well-known medical officer formerly stationed at Thursday Island is reported to have died as a result of a sting from this creature; but information supplied by his son indicates clearly that this was not the case."

In contradistinction to the late Dr Flecker's assertion of "no authenic record" of death due directly to stone fish venom is the zoologist J L B ('Coelocanth') Smith's 1957(6) account of two deaths caused by species identified as Synanceja verrucosa in the Indian Ocean. One involved a previously healthy 15 year-old boy in the Seychelles who died in March 1956 shortly after being punctured in the foot by stone fish spines, indicating a direct effect of the envenomation as being the cause of death rather than a later septicaemia. The other fatality involved an adult man who died within an hour of standing on a Stonefish at Pinda, Mozambique. This time-scale indicates the same mode of causation of death.

Seventy five years after the event one is left with the impression that Dr Wassell's death was due to septicaemia, occurring as it did "within a few days"(4) of his standing on the stone fish. No case notes survive at Thursday Island Hospital (Dr P Holt - personal communication) and expert opinion (Dr S K Sutherland - personal communication) concurs with the above view, on the basis that integumentary material and pathogenic marine bacteria are frequently found in human skin which has been punctured by stone fish spines(3). Nevertheless the whole saga illustrates just how different the actual chain of events was from the statement on the memorial.

Military records are however still extant and show that Dr Wassell was born on 11th January 1874 . He held the rank of Captain (provisional) AAMC at the time of being appointed "to perform the duties of Naval Medical Officer, Thursday Island, in addition to his military duties with an allowance at the rate of $£ 30$ per annum. Dated 1st October 1912"(7). His provisional rank of Captain AAMC was confirmed as full rank on 1st October 1913(8).

Thursday Island was extensively fortified with emplacements for heavy guns at the end of the last century in order to counter a perceived threat to Australia from the Imperial Russian Navy(2). By 1914 the identity of the enemy had changed, and Thursday Island formed part of an important line of communication between continental Australia and the small but strategically vital campaign which captured German New Guinea. The loss of Thursday Island's quarantine and health officer who was also the local military and naval medical officer could hardly have occurred at a more inconvenient time.

\section{Acknowledgments:}

I thank Warren Hann RN, Nursing Superintendent of Thursday Island Hospital for providing the photographs of Dr Wassell's memorial, and the Department of Medical Illustration, Royal Army Medical College for reproducing them for publication in the Journal.

\section{REFERENCES}

1. Maugham W S. "French Joe" in Collected Short Stories. Vol IV. London: Pan Books, 1976, page 31.

2. Lucas A. Cruising the Coral Coast. 3rd ed. Melbourne: Horwitz, 1976:336.

3. Sutherland S K. Australian Animal Toxins: the creatures, their toxins and care of the poisoned patient. Melbourne: Oxford University Press, 1983:440.

4. Whitley G P. Dangerous Australian Fishes in The Postgraduate Bulletin of the Medical Committee of the University of Sydney, March 1963:48.

5. FleCKER H. Injuries from Stone Fish. Med J Aust 1956;371.

6. SMith J L B. Two Rapid Fatalities from Stone Fish stabs. Copeia $1957 ; 249$.

7. Commonwealth Gazette (Australia) 16 November 1912;74:2508.

8. Gradation List of Officers of the Commonwealth Military Forces, Department of Defence Central Army Records Office, Melbourne, Australia 3004, 1913;300:364. 